\title{
A Review Study on Effect of Steel Fibre and Marble Dust with Strength of Pavement Quality Concrete
}

\author{
Krishan Kumar \\ MTech Scholar - Department of Civil Engineering \\ Om Institutes of Technology \& Management, \\ Juglan Hisar (Haryana)
}

\author{
Sumesh Jain \\ Asst Professor, Department of Civil Engineering Om \\ Institutes of Technology \& Management, \\ Juglan Hisar (Haryana)
}

\section{ABSTRACT}

There is growing interest in the construction of concrete pavements, due to its high strength, durability, better serviceability and overall economy in the long run. The thrust nowadays is to produce thinner and green pavement sections of better quality, which can carry the heavy loads. The high strength steel fibre reinforced concrete is a concrete having compressive strength greater than $40 \mathrm{MPa}$, made of hydraulic cements and containing fine and coarse aggregates; and discontinuous, unconnected, randomly distributed steel fibres. The present study aims at, developing pavement quality concrete mixtures incorporating marble dust as partial replacement of cement as well as steel fibres. The aim is to the design of slab thickness of PQC pavement using the achieved flexural strength of the concrete mixtures. In this study, the flexural, compressive and split tensile strength for pavement quality concrete mixtures for different percentage of steel fibres and replacement of cement with marble dust are reported. It is found out the maximum increase in flexure strength, compressive strength and split tensile strength is for $0 \%$ Marble Dust and 1\% Steel fibre. Also it has been possible to achieve savings in cement by replacing it with marble dust and adding fibres. This study also shows that in view of the high flexural strength, high values of compressive strength and high values of split tensile strength, higher load carrying capacity and higher life expectancy, the combination of 10 to $20 \%$ marble dust replacement along with addition of 0.5 to $1 \%$ steel fibres is ideal for design of Pavement Quality Concrete (PQC).

\section{INTRODUCTION}

The word concrete comes from the Latin word "concretus" (meaning compact or condensed), the perfect passive participle of "concrescere", from "con-
" (together) and "crescere (to grow). During the Roman Empire, roman concrete (or opus caementicium) was made from quicklime, pozzolana and an aggregate of pumice. Concrete is a composite construction material composed primarily of aggregate, cement and water. There are many formulations that have varied properties. The aggregate is generally coarse gravel or crushed rocks as limestone, or granite, along with a fine aggregate such as sand. The cement, commonly Portland cement and other cementitious materials such as fly ash and slag cement serve as a binder for the aggregate. Various chemical admixtures are also added to achieve varied properties. Water is then mixed with this dry composite which enables it to be shaped (typically poured) and then solidified and hardened into rock-hard strength through a chemical process known as hydration. The water reacts with the cement which bonds the other components together, eventually creating a robust stone like material. Concrete has relatively high compressive strength. For this reason is usually reinforced with materials that are strong in tension (often steel). Concrete can be damaged by many processes, such as the freezing of trapped water. The environmental impact of concrete is a complex mixture of not entirely negative effects; while concrete is a major contributor to greenhouse gas emissions, recycling of concrete is increasingly common in structures that have reached the end of their life. Structures made of concrete can have a long service life. As concrete has a high thermal mass and very low permeability, it can make for energy efficient housing. As we know Concrete is a versatile construction material. Firstly it was innovated as protective cover of steel members, after that it was revised and now a day's concrete is used as a structural member and steel is provided to modify its properties and give better strength to the concrete. 


\section{www.ijtsrd.com}

Concrete has benefits like fire resistance, excellent resistance to water, has ability to mould into various shapes and sizes easily as per requirement, economic and readily available material on the job site. It was observed that the normal concrete have many inadequacy such as low value of strength to weight ratio as compared to steel. So as to overcome this inadequacy resulted in the development of high strength concrete (HSC).

\section{LITERATURE REVIEW}

Wang et al. (1996), investigated the fibre reinforced concrete beams under impact loading. Impact tests were carried out on small concrete beams reinforced with different volumes of both polypropylene and steel fibres. The drop height of the instrumented drop weight impact machine was so chosen that some specimens failed completely under a single drop of the hammer, while others required two blows to bring about complete failure. It was found that, at volume fractions less than $0.5 \%$, polypropylene fibres gave only a modest increase in fracture energy.

Furlan and Bento (1997), analyzed the influence of fibres on the structural performance in situations of different ratios of shear reinforcement, some aspects of the properties of fresh and hardened concrete are introduced. The main alterations resulting from the use of fibres were increased shear strength, stiffness (particularly after first cracking stage) and ductility.

Elsaigh et al. (2005),carried out investigation on steel fibre reinforced concrete for road pavement applications. In this paper, they established that the use of SFRC for road pavements and compare its execution with plain concrete under traffic loading. The determining of SFRC properties on performance and design aspects of concrete roads are discussed. Results coming out from road trial sections, tested under in-service traffic, are used to validate the use of the material in roads.

Wegian et al. (2011), studied on the influences of fly ash on behaviour of fibre reinforced concrete structures. The aim of this study was to measure the tensile and compressive strength of concrete with different steel fibre and fly ash percentage. Concrete specimens with different fibre contents like $0.50 \%$, $1 \%$ and $1.5 \%$ by volume were tested. Fly ash contents in mixes ranged $\mathrm{b} / \mathrm{w} 0$ and $30 \%$ by weight. Sixteen concrete mixes were prepared. The result of this study confirmed that the addition of steel fibre has a negligible effect on the compressive strength of concrete but it improves the flexural strength. factor, span to depth ratio, longitudinal steel ratio and size effect is considered.

Khan et al. (2013),performed on steel fibres to increase the load carrying capacity of concrete members. Fibres substantially reduce the brittleness of concrete and improve its engineering properties, such as tensile, flexural, impact resistance, fatigue, load bearing capacity after cracking and toughness.

\section{MATERIAL \\ AND \\ DESIGN METHODOLOGY}

\section{Portland Cement}

Although all materials that go into concrete mix are essential, cement is very often the most important because it is usually the delicate link in the chain. The function of cement is first of all to bind the sand and stone together and second to fill up the voids in between sand and stone particles to form a compact mass. It constitutes only about 20 percent of the total volume of concrete mix; it is the active portion of binding medium and is the only scientifically controlled ingredient of concrete. Any variation in its quantity affects the compressive strength of the concrete mix. Portland cement referred as (Ordinary Portland Cement) is the most important type of cement and is a fine powder produced by grinding Portland cement clinker. The OPC is classified into three grades, namely 33 Grade, 43 Grade, 53 Grade depending upon the strength of 28 days.

\section{Aggregate}

Aggregates constitute the bulk of a concrete mixture and give dimensional stability to concrete. To increase the density of resulting mix, the aggregates are frequently used in two or more sizes. The most important function of the fine aggregate is to assist in producing workability and uniformity in mixture. The fine aggregate assist the cement paste to hold the coarse aggregate particles in suspension. This action promotes plasticity in the mixture and prevents the possible segregation of paste and coarse aggregate, particularly when it is necessary to transport the concrete some distance from the mixing plant to placement. The aggregates provide about $75 \%$ of the body of the concrete and hence its influence is extremely important. They should therefore meet 
certain requirements if the concrete is to be workable, strong, durable and economical. The aggregates must be proper shape, clean, hard, strong and well graded.

a) Coarse Aggregates: The aggregate which is retained over IS Sieve $4.75 \mathrm{~mm}$ is termed as coarse aggregate. The coarse aggregates may be of following types:-

i) Crushed graves or stone obtained by crushing of gravel or hard stone.

ii) Uncrushed gravel or stone resulting from the natural disintegration of rocks.

iii) Partially crushed gravel or stone obtained as product of blending of above two types.

\section{Properties of Coarse Aggregates}

\begin{tabular}{|l|l|}
\hline \multicolumn{1}{|c|}{ Characteristics } & \multicolumn{1}{c|}{ Value } \\
\hline Colour & Grey \\
\hline Shape & Angular \\
\hline Maximum Size & $20 \mathrm{~mm} / 10 \mathrm{~mm}$ \\
\hline Specific Gravity & $2.73 / 2.72$ \\
\hline Water Absorption & $0.20 \% / 0.35 \%$ \\
\hline
\end{tabular}

b) Fine Aggregates: The aggregates most of which pass through $4.75 \mathrm{~mm}$ IS sieve are termed as fine aggregates. The fine aggregate may be of following types:

i) Natural sand, i.e. the fine aggregate resulting from natural disintegration of rocks.

ii) Crushed stone sand, i.e. the fine aggregate produced by crushing hard stone.

iii) Crushed gravel sand, i.e. the fine aggregate produced by crushing natural gravel.

According to size, the fine aggregate may be described as coarse, medium and fine sands. Depending upon the particle size distribution IS: $383-$ 1970 has divided the fine aggregate into four grading zones.

\section{c) Marble Dust}

Marble dust was collected from different site. It was white in colour and it was air dried and powder in form.

\section{d) Steel Fibre}

Mild steel fibres having $30 \mathrm{~mm}$ thickness and $60 \mathrm{~mm}$ length i.e. aspect ratio $(1 / \mathrm{d}) 50$ which are corrugated and obtained through cutting of steel wires have been used. The fibres have been cut

\section{SUPERPLASTICIZER}

Super-plasticizers constitute a relatively new category and improved version of plasticizer. They are chemically different from normal plasticizers. Use of super-plasticizer permits the reduction of water to the extent up to 30 percent without reducing workability in contrast to possible reduction up to 15 percent in case of plasticizers. The mechanism of action of super-plasticizer is more or less same as in case of ordinary plasticizer. The super-plasticizers are more powerful as dispersing agents and they are high water reducers. It is use of super-plasticizer which has made it possible to use w/c as low as 0.25 or even lower and yet to make flowing concrete to obtain compressive strength of the order of $120 \mathrm{MPa}$ or more (Shetty 2005). It is the use of super-plasticizer which has made it possible to use fly ash, slag and particularly silica fume to make high performance concrete.

\section{WATER}

The potable water is generally considered satisfactory for mixing and curing of concrete. Accordingly potable water was used for making concrete available in Material Testing laboratory. This was free from any detrimental contaminants and was good potable quality.

\section{TEST METHODS}

\section{Specific Gravity}

2 Sieve Analysis for Coarse and Fine Aggregates

3 Compressive Strength of Concrete

4 Split Tensile Strength of Concrete

\section{CONCLUSIONS}

From the experimental results, the following conclusion can be drawn: 
International Journal of Trend in Scientific Research and Development, Volume 1(4), ISSN: 2456-6470 www.ijtsrd.com

\section{Strength Characteristics}

$>$ Concrete mix with 10 percent marble dust as replacement of cement is the optimum level as it has been observed to show a significant increase in compressive strength at 28 days when compared with nominal mix.

$>$ Concrete mixes when reinforced with steel fibre show an increased compressive strength as compared to nominal mix.

$>$ The split tensile strength also tends to increase with increase percentages of steel fibres in the mix.

$>$ On increasing the percentage replacement of cement with marble dust beyond $10 \%$, there is a slight reduction in the tensile strength value.

$>$ The flexure strength also tends to increase with the increase percentages of steel fibres, a trend similar to increase in split tensile strength and compressive strength.

$>$ On increasing the percentage replacement of cement with marble dust beyond $10 \%$, there is decrease in the flexure strength value.

Maximum strength (flexure, compressive as well as split tensile) of pavement quality concrete incorporating marble dust and steel fibres, both, is achieved for $10 \%$ marble dust replacement and $1 \%$ steel fibres. However, if the marble dust content is increased to $20 \%$, even with $1 \%$ steel fibre, the increase is not very significant.

\section{REFERENCES}

1. Achilleos, Constantia, et al. "Proportioning of steel fibre reinforced concrete mixes for pavement construction and their impact on environment and cost."Sustainability 3.7 (2011): 965-983.

2. Aukour, Fakher J. "Incorporation of marble sludge in industrial building eco-blocks or cement bricks formulation." Jordan Journal of Civil Engineering 3.1 (2009): 58-65

3. Baboo, Rai, et al. "Influence of Marble powder/granules in Concrete mix."International Journal of Civil \& Structural Engineering 1.4 (2010): 827-834.

4. Bhikshma, V., K. Nitturkar, and Y. Venkatesham. "Investigations on mechanical properties of high strength silica fume concrete." Asian Journal of
Civil Engineering (Building and Housing) 10.3 (2009): 335-346.

5. Chunxiang, Qian, and IndubhushanPatnaikuni. "Properties of high-strength steel fiber-reinforced concrete beams in bending." Cement and Concrete Composites 21.1 (1999): 73-81.

6. Corinaldesi, Valeria, GiacomoMoriconi, and Tarun R. Naik. "Characterization of marble powder for its use in mortar and concrete." Construction and Building Materials 24.1 (2010): 113-117.

7. Demirel, Bahar. "The effect of the using waste marble dust as fine sand on the mechanical properties of the concrete." International Journal of the Physical Sciences 5.9 (2010): 1372-1380.

8. Elsaigh, WA, Kearsley, EP and Robberts , JM. “ Steel Fibre Reinforced Concrete For Road Pavement Application". Paper Presented to the 24 th Annual Southern African Transport Conference (2005), South Africa.

9. G.Murali, C.M. VivekVardhan, P. Sruthee, P. Charmily. "Influence of Steel Fibre on Concrete." International Journal of Engineering Research and Applications (IJERA) ISSN:

2248-9622 (2012), Vol. 2, Issue 3, pp.075-078.

10. Hameed, M. Shahul, and A. S. S. Sekar. "Properties of green concrete containing quarry rock dust and marble sludge powder as fine aggregate." ARPN J. Eng. Appl. Sci 4.4 (2009): 8389. 